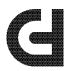 \\ COUNTERFUTURES \\ Left thought \& practice Aotearoa
}

\section{THREE}




\section{Demanding Explanations ${ }^{1}$}

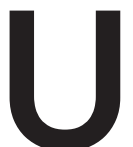

NDERSTANDING CRIME FREQUENTLY means explaining the who, how, and why of offending behaviour. It is an intellectually demanding exercise because of the considerable array of drivers that can conceivably bear upon individual acts of crime, let alone fields of criminal activity. Moreover, the complexity increases further when we factor in the matter of who is allowed to enact a crime without it being named as such. The state's ability to break the generalised prohibition on killing is an old chestnut in this regard. Another way of interpreting this latter point is that the development of understanding depends, in part, on the social power of the one demanding explanation. This nub of demanding/demand counts. It has real effects in how state policy on crime and punishment forms and on how political activism proceeds in response to such policy. For these reasons,

1 Many thanks to Gregor McLennan for this phrase. 
160 | Counterfutures 3

the arguments are pursued vigorously. The following began as a book review, by Ronald Kramer of Greg Newbold's book Crime, Law and Justice in New Zealand. Kramer agreed to a response from Newbold. Vigorous debate followed. (Eds.) 


\title{
Crime, Law and Justice in New Zealand
}

\section{By Greg Newbold, Routledge, 2016}

\author{
Ronald Kramer
}

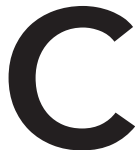

rime, Law and Justice in New Zealand seeks to explain trends in crime and criminal justice by situating these in their broader 'social, economic, cultural and political environment'. ${ }^{2}$ The text is a rich historical document, and does a thorough job of charting major crime-related events from New Zealand's history. The book unfolds through an exploration of specific types of crime, such as dishonesty offenses, violent crime, sexed violence, and gangs and organized crime. Each of these chapters is replete with discussions of relevant legislation and how it has changed over time, official figures on crime, and specific criminal events that, for one reason or another, came to occupy a prominent place in the public's consciousness on crime. Insofar as the text is comprehensive and loaded with

2 Greg Newbold, Crime, Law and Justice in New Zealand, New York 2016, p. 253. 
factual information concerning specific crime types, it provides a good overview; one that readers could easily use to develop a general picture of crime in New Zealand. Scholars, especially those who are new and hoping to enter the fields of criminology and sociology, might also benefit from Crime, Law and Justice in New Zealand as it provides many useful starting points for further, in-depth research into the particular forms of crime that it covers. The text would direct such readers to important legislative shifts and prominent instances of criminal activity.

Against these strengths, however, the text is beset by a number of closely related limitations. Although it promises to situate crime and criminal justice in its broader social contexts, this is often done in ways that seem arbitrary, lack substantive empirical foundation and, to put it mildly, are ideologically loaded. Supposed increases in violent offenses committed by women, for example, are attributed to feminist movements that encouraged new forms of self-identity and fought against women's 'second class' status. The final section of the chapter entitled 'Sex' is especially problematic. Readers could easily come away from this section accepting the notion that anywhere from 30 to 80 percent of rape allegations made by women are false. This claim appears to be based on some concrete instances, 'senior police' official quoted in the New Zealand Herald, ${ }^{3}$ and the fact that relatively few rape allegations lead to criminal prosecutions.

While Newbold does include some caveats here'sometimes rape victims withdraw legitimate complaints" - there is no discussion of the cultural structures and legal frameworks that often exonerate men's violence and make prosecution of rape difficult. Instead, we are told: 
One of the reasons that police and prosecutors decide a case should be dropped is that the complainant's allegations are confused, inconsistent, unreliable or contradicted by other available evidence. In other words, they decide that the complainant may be mistaken or lying. ${ }^{5}$

Such a position, apparently, does not seem to warrant scrutiny. Indeed, Newbold quickly proceeds to endorse the idea that rape victims have a propensity to lie:

This section, I think, provides a supporting argument for the status quo. Every year, thousands of hours of police time are wasted investigating false complaints and thousands of dollars are spent by falsely accused persons trying to clear their names. The trauma of having to defend oneself against the trauma of a false allegation of rape may be just as great as that of rape itself. ${ }^{6}$

This conclusion is all the more perplexing given that, in the sentences that immediately follow, Newbold points out that although police records indicate around 444 false complaints have been made over the last five years, there 'are no records indicating what the complaints related to'. ${ }^{7}$

Presumably, any critical feminist scholar worth his or her salt will be unimpressed by Newbold's perspective. Likewise, there is a very strong chance that those interested in the relationship between race/ethnicity and criminal justice will be dismayed by many of the interpretative glosses found within Crime, Law and Justice in New Zealand. The chapter on 'Youth and Ethnicity' closes by advancing a 'culture of poverty' type argument to explain Māori offending rates:

5 Ibid., p. 97.

6 Ibid., p. 99.

7 Ibid., p. 99. Emphasis added. 
To re-cap, Maori are considerably more likely to drink at hazardous levels, are more likely to be regular cannabis users .... Maori children are twice as likely to be abused .... Another factor that is likely to impact on the likelihood of a child offending is young motherhood .... Maori girls are more than four times as likely to give birth before they reach the age of 18 as non-Maori .... Maori are almost four times as likely to be unemployed ... and are more likely to have left school without any qualifications. Maori at school have a higher rate of absenteeism than any other ethnic group ...8

Alongside recourse to long discredited arguments of this type, the text often trots out well-worn 'Māori deficit statistics.' At numerous points, we are reminded that Māori and Pasifika peoples are over-represented within the criminal justice system, especially in terms of incarceration rates, but little is done to contextualize this:

More than half of all incarcerated are Maori, with Pakeha only constituting one-third of those incarcerated and Pasifika 11.3 per cent. This is not new: Maori have comprised about half of all incarcerated since the early 1980 s. $^{9}$

I think the meaning of 'new' is up for debate here. Were the early 1980s not a time of fundamental upheaval in the political economies of so-called western democracies? Was this not a period in which class inequalities and racial disparities were exacerbated as states came to bolster punitive institutions to control socially marginalized groups? Given the theoretical orientations that undergird much of the text, I suppose one should not be too surprised to find that the incarceration rates of Māori and Pasifika 
peoples elude contextualization. Colonialism and neoliberalism, for example, are not to be found in the book's index.

The book would have been much improved if it were written as a dispassionate history of crime and criminal justice in New Zealand, preferably one that excluded most of Newbold's efforts to theorize such a history. As noted, the text promises to understand trends in crime by referencing broader cultural, political, economic, and social forces, but Newbold populates his concept of social structure with progressive social movements, aesthetic violence within popular culture, youthful rejections of the 'protestant work ethic', and cultural stereotypes. This is not what sociologists of crime/deviance typically have in mind when they seek to understand the relationship between structure, crime, and criminal justice.

There is simply too much historical detail in this textdetail that pertains to very disparate types of behaviour-to allow for meaningful and substantiated theoretical claims to simultaneously be developed and demonstrated. This leads to a text that brings patterns of offending into the orbit of social forces, but does so without providing the empirical evidence required to support such assertions. Assuming that women's use of violence has spiked in recent times, for example, how do we know their lives and/or sense of self have been altered by progressive women's movements? Considering whether the content of popular culture can be linked to increases in violence might make sense (see chapter 5), but positing an actual relationship between the two requires evidence: What do we know about the cultural consumption habits or cultural orientations of those who engage in violence? These kinds of empirical details are not canvased. Without them, however, any theoretical interpretations remain speculative at best.

Those considering a textbook for criminology and/or sociology courses will need to seriously consider how a work of 
this nature can be incorporated. The historical detail is certainly valuable given the lack of contemporary, New Zealand specific texts, but how to negotiate the book's theoretical limitations and apologetic, ideological undertows? 


\title{
Response to Kramer
}

\author{
By Greg Newbold
}

HE TONE OF Ron Kramer's review of my recent book, Crime, Law and Justice in New Zealand was not unexpected, radical feminists at Canterbury University have made some similar comments. Kramer spends half a page of his review commending the book for its factually-based treatment of changes in crime patterns since WWII, but then launches into a lengthy critique of small sections of it. The critique, which focuses on just a few pages of this 285-page title, occupies over $80 \%$ of the review. Thus I suggest the review is unbalanced.

The critique refers to two principal areas. First Kramer says that my discussion about false rape complaints is ideologically loaded' and 'lacks empirical foundation'. Well any discussion about false rape complaints is bound to lack empirical foundation because there are no solid facts on the subject, there is absolutely no way of determining what percentage of rape complaints are actually true or false. All we have are widely disparate guesses. 
As I note, different police sources have estimated that $30 \%$ to $80 \%$ of complaints are false, although personally I think $80 \%$ is too high. Some feminist sources suggest up to $12 \%$ may be falseprobably too low in my view, but who knows? It is a loaded area and whatever position is taken on it, dissenting parties will accuse the other of ideological bias. This is what Kramer has done. Over the years I have collected a large dossier containing hundreds of proven cases of false and malicious rape complaints-a few of which I reproduce in the book-and all I have done here is argue for continued caution regarding such complaints, and for retention of the presumption of the innocence with a high standard of proof. Kramer takes issue with this, but if he is suggesting, as others have, that we should alter the onus and standard of proof in rape cases, then the accusation of ideological bias certainly applies to him.

The second area of contention concerns my discussion of the significant over-representation of Māori (and Pasifika) in criminal justice statistics, as well as in alcohol abuse and domestic violence. This over-representation is well known and is commented on in every relevant government and private research publication I have read. I supply numerous references in the book. Part of the explanation, I suggest, is related to poverty and class, which Kramer, somewhat puzzlingly, dismisses as a 'long discredited argument'. Oh? It's the first time I've ever heard of the poverty/crime relationship being a long discredited argument. Perhaps I am out of date.

Kramer disagrees with a statement on page 239 of my book, that holds over-representation of Māori in prison statistics is not new. He says that the use of the word 'new' is debatable since Māori have only constituted $50 \%$ of the prison population since the early 1980s, which, he reminds us, was a time when 'class inequalities and racial disparities were exacerbated as states came to bolster punitive institutions to control socially 
marginalised groups'. Really? And that did not happen before? Apparently he is unaware that Māori over-representation in prison statistics has existed since 1936, and has been increasing since then. The problem certainly is not new.

Finally, Kramer attacks my failure to trot out the old, tired explanation for Māori and Pasifika over-representation in crime and domestic violence as being a result of 'colonialism and neoliberalism'. I expected that. But I deliberately refrained from engaging in such discussion because although popularly and often uncritically accepted in academic circles, the argument is weak on empirical substance. Of course I have read these arguments in their various guises over the years, but as a former anthropologist I have found them to suffer from over-reliance on contentious information, cultural misunderstanding, questionable logic, over-generalisation, and, occasionally, falsehood. The colonialism thesis cannot be empirically tested and cannot explain why the same problems - high crime rates, high levels of domestic violence and alcohol abuse - exist throughout Oceania, even in nations which have been self-governing for decades and in countries like Tonga that have never been colonialised at all. To use Kramer's own terminology, the colonialism argument is short on empirical evidence and is ideologically loaded. That is why I steered clear of it.

Kramer finishes off with a general broadside by way of summation. He criticises me for attempting to theorise the history of crime and justice in New Zealand. I attempt no such thing, anywhere. Moreover, having praised the book in the first two paragraphs for its wealth of data and historical information, he now says that there is 'too much historical detail' and that I make assertions 'without providing [the necessary] empirical evidence'. As an example, he says that I link rising women's violence with the progressive feminist movement. I do not. In fact, the women most frequently arrested for violent behaviour come 
from the sectors of society that have been least affected by the women's movement. The tentative link I do make regarding rising working class and Māori/Pasifika women's violence is with the rise of the action heroine in popular media. That is all. I am, of course, not alone in this; the idea is well canvassed in the literature. UC sociology lecturer Tiina Vares reviewed much of it in her $\mathrm{PhD}$ thesis and has also published on it. But Kramer questions whether there is any evidence to support the notion.

Crime, Law and Justice in New Zealand is the culmination of 40 years' experience and research into the history and development of crime and law in this country. It is the only book of its type ever written here. After Routledge accepted the manuscript it distributed the text for blind review with several academic specialists in Australia and New Zealand. I made a number of adjustments and amendments as a result of their feedback. Routledge then sent the manuscript out to a different set of specialists for a second review. All praised the book and recommended publication as is. Since its release I have received unsolicited congratulations from management and policy executives in the departments of police, justice, and corrections. But because it conflicts with his leftist-liberal ideology, Ron Kramer sees the book as of limited value to students. However, students at UC love it and senior policy makers in New Zealand's justice sector have described it as useful and informative. In retrospect, had I been able to read Kramer's review prior to publication, I would have changed nothing. 
If you like what you have read, please subscribe or donate.

\author{
G \\ COUNTERF UTURES \\ Left thought \& practice Aotearoa \\ (C) Copyright Counterfutures 2017
}

